\title{
IbM PENDAMPINGAN DAN PEMBIMBINGAN OLIMPIADE MATEMATIKA BERBASIS STRATEGI PEMECAHAN MASALAH POLYA PADA SISWA SMK MUHAMMADIYAH 2 MALANG
}

\author{
Alfiani Athma Putri Rosyadi ${ }^{*}$, Reni Dwi Susanti ${ }^{2}$, Mayang Dintarini ${ }^{3}$ \\ ${ }^{1 *}$ Pendidikan Matematika, Universitas Muhammadiyah Malang \\ ${ }^{2}$ Pendidikan Matematika, Universitas Muhammadiyah Malang \\ ${ }^{3}$ Pendidikan Matematika, Universitas Muhammadiyah Malang \\ ${ }^{*}$ Corresponding author \\ E-mail:athmaputri@gmail.com
}

Diterima 2 November 2018, Disetujui 7 November 2018

\begin{abstract}
ABSTRAK
SMK Muhammadiyah 2 Malang merupakan sekolah yang telah memulai pembimbingan secara intens untuk siswa-siswa berbakat dalam bidang matematika dalam kegiatan pembimbingan olimpiade. Pembimbingan olimpiade ini merupakan hasil kerjasama pihak sekolah dengan tim pengabdian. Namun perlu ada pengembangan dari pengabdian terhadap pembimbingan olimpiade yang telah berjalan, yaitu pada aspek strategi penyelesaian masalah matematika, yang wajib diketahui oleh guru dan siswa itu sendiri. Strategi penyelesaian masalah ini penting diketahui untuk menunjang siswa dalam mengikuti berbagai ajang kompetisi matematika. Luaran yang diharapkan dari kegiatan pengabdian ini yaitu adanya Modul materi olimpiade berdasarkan strategi Polya. Pada tahap implementasi, luaran yang dihasilkan yaitu dan catatan hasil pembinaan Materi Olimpiade Matematika SMK Muhamamdiyah 2 Malang.
\end{abstract}

Kata Kunci: Pendampingan, Pembimbingan, Olimpiade Matematika, Strategi Pemecahan Masalah Polya.

\begin{abstract}
Muhammadiyah 2 Malang Vocational School is a school that has started intense coaching for gifted students in the field of mathematics in Olympic guidance activities. The Olympic guidance is the result of the collaboration between the school and the service team. But there needs to be a development of devotion to olympiad guidance that has been running, namely on aspects of the strategy of solving mathematical problems, which must be known by the teacher and the students themselves. The strategy to solve this problem is important to know to support students in participating in various mathematical competitions. The expected output of this service activity is the existence of an Olympic material module based on Polya's strategy. At the implementation stage, the output produced is and records the results of the development of Mathematical Olympiad Material at Muhammadiyah 2 Vocational School in Malang.
\end{abstract}

Keywords: Mentoring, Mentoring, Mathematics Olympiad, Polya Problem Solving Strategy.

\section{PENDAHULUAN}

Beragam karakteristik siswa dapat ditemui di dalam kelas, khusunya kelas matematika. Siswa berbakat (gifted student) merupakan salah satu siswa yang dapat ditemui dalam kelas matematika. Bicknell (2008) mengemukakan siswa berbakat dalam kelas matematika yaitu siswa yang memiliki curiosity dan pemahaman tentang aspek kuantitatif, memiliki kemampuan berpikir logis, memahami aspek simbolik, memahami hubungan kualitatif dan spasial, memiliki kemampuan menggeneralisasi pola, struktur, relasi, dan operasi matematika, memiliki kemampuan menalar secara analitik, deduktif, dan induktif, mampu menyelesaikan masalah kehidupan sehari-hari yang berkaitan dengan matematika secara rasional, memiliki keluwesan dalam menyelesaikan kegiatan matematika, memiliki kemampuan mengingat simbol-simbol, metode penyelesaian, hubungan dan bukti dalil-dalil, memiliki motivasi yang tinggi dalam menyelesaikan masalah matematika, serta memiliki persepsi matematis terhadap dunia.

Siswa berbakat berbeda dari kebanyakan siswa lainnya. Salah satu perbedaannya terletak pada cara siswa menyelesaikan masalah. Guru harus memiliki cara tersendiri 
untuk memfasilitasi pola pikir siswa tersebut. Guru juga perlu menyiapkan strategi untuk mengasah bakat yang dimiliki oleh siswa. Salah satu yang dapat guru lakukan untuk mengasah bakat tersebut adalah dengan melakukan pembimbingan intensif terhadap siswa berbakat.

Polya dalam Kennedy \& Johnson (2007) mengemukakan bahwa terdapat empat langkah dalam memecahkan masalah matematika, yaitu mengidentifikasi masalah, mengusulkan solusi, melaksanakan rencana penyelesaian, dan evaluasi. Selain itu terdapat sebelas strategi yang umum dilakukan untuk menyelesaikan masalah matematika, yaitu mencari dan menggunakan pola, mensimulasikan permasalahan, membuat model, menggambar diagram, membuat tabel atau grafik, menuliskan kalimat matematika, trial and error, menuliskan semua kemungkinan jawaban, menyelesaikan permasalahan yang lebih sederhana, bekerja mundur, dan mengubah sudut pandang.

SMK Muhammadiyah 2 Malang, merupakan sekolah yang telah memulai pembimbingan secara intens untuk siswasiswa berbakat dalam bidang matematika dalam kegiatan pembimbingan olimpiade. Pembimbingan olimpiade ini merupakan hasil kerjasama pihak sekolah dengan tim pengabdian. Namun perlu ada pengembangan dari pengabdian terhadap pembimbingan olimpiade yang telah berjalan, yaitu pada aspek strategi penyelesaian masalah matematika, yang wajib diketahui oleh guru dan siswa itu sendiri. Strategi penyelesaian masalah ini penting diketahui untuk menunjang siswa dalam mengikuti berbagai ajang kompetisi matematika.

Tabel 1. Hasil Evaluasi Pendampingan Kegiatan Sebelumnya

\begin{tabular}{|c|c|c|}
\hline Aspek & $\begin{array}{l}\text { Sebelum } \\
\text { kegiatan } \\
\text { pengabdian }\end{array}$ & $\begin{array}{l}\text { Sesudah } \\
\text { kegiatan } \\
\text { pengabdian }\end{array}$ \\
\hline $\begin{array}{l}\text { Sistem } \\
\text { Pembimbi } \\
\text { ngan }\end{array}$ & $\begin{array}{l}\text { Belum } \\
\text { terjadwal. } \\
\text { Terbatas pada } \\
\text { pertemuan guru } \\
\text { murid di } \\
\text { sekolah. }\end{array}$ & $\begin{array}{l}\text { Terjadwal. } \\
\text { Tidak terbatas } \\
\text { pada } \\
\text { pertemuan guru } \\
\text { murid di } \\
\text { sekolah, kerena } \\
\text { guru murid } \\
\text { dapat } \\
\text { melakukan } \\
\text { interaksi } \\
\text { melalui } \\
\text { software } \\
\text { EDMODO. }\end{array}$ \\
\hline
\end{tabular}

\begin{tabular}{|l|l|l|}
\hline Handout & $\begin{array}{l}\text { Belum tersedia } \\
\text { handout }\end{array}$ & $\begin{array}{l}\text { Telah tersedia } \\
\text { handout }\end{array}$ \\
\hline Prestasi & - & $\begin{array}{l}10 \text { besar ME } \\
\text { Awards di } \\
\text { Lampung } \\
\text { Tahun 2017 }\end{array}$ \\
\hline $\begin{array}{l}\text { Kemampu } \\
\text { an guru }\end{array}$ & $\begin{array}{l}\text { Belum } \\
\text { memahami } \\
\text { cara } \\
\text { membimbing } \\
\text { olimpiade. }\end{array}$ & $\begin{array}{l}\text { Telah } \\
\text { memahami } \\
\text { cara } \\
\text { membimbing } \\
\text { olimpiade } \\
\text { secara umum. }\end{array}$ \\
\hline
\end{tabular}

Pada pembimbingan olimpiade di SMK Muhammadiyah 2 Malang, belum mengetahui penerapan sebelas strategi pemecahan masalah matematika menurut teori Polya. Sehingga guru mengajarkan bagaimana menyelesaikan soal olimpiade yang merupakan masalah matematika dengan cara dan strategi yang umum dan tidak terorganisir. Pengadaan handout berbasis Teori Polya juga dianggap penting untuk disusun agar siswa dapat lebih memahami penerapan strategi pemecahan masalah Polya tersebut.

Pembimbingan olimpiade di SMK 2 Muhammadiyah sudah menggunakan Edmodo sebagai solusi keterbatasan waktu pembimbingan di sekolah, sehingga guru tetap bisa memantau proses pembelajaran dan siswa tetap terlibat aktif dalam pembelajaran meskipun di luar sekolah. Bimbingan online dilakukan langsung oleh guru dengan siswa, dimana guru dengan aktif memberikan soalsoal olimpiade dalam aplikasi Edmodo untuk diselsesaikan oleh siswa, kemudian dibahas saat pertemuan rutin di sekolah. Oleh karena itu, pendampingan dan pembimbingan olimpiade matematika berbasis strategi pemecahan masalah Polya pada siswa SMK Muhammadiyah 2 Malang dirasa sangat perlu dilakukan, guna meningkatkan prestasi siswa SMK 2 Muhammadiyah Malang dalam berbagai ajang kompetisi olimpiade Matematika.

\section{METODE PELAKSANAAN}

Metode pelaksaaan dari kegiatan Pendampingan dan Pembimbingan Olimpiade Matematika ini terdiri dari beberapa tahapan kegiatan. Kegiatan tersebut dimulai dari kegiatan persiapan, kegiatan sosialisasi, kegiatan pendampingan penyusunan Handout, Implementasi dan Analisis keterlaksanaan. Adapun uraian dari masing-masing kegiatan adalah sebagai berikut:

1. Persiapan

Kegiatan persiapan ini dimulai dengan kegiatan observasi guna mengetahui 
kondisi di sekolah berkaitan dengan kegiatan pendampingan olimpiade dan bagiaman sistematika pendampingan yang dilakukan di sekolah. Kegiatan persiapan ini juga dilakukan dengan kegiatan wawancara terhadap pihak sekolah yaitu waka kurikulum dan guru bidang studi. Berdasarkan hasil observasi dan wawancara tersebut, tim pengabdian melakukan diskusi internal dan mengkaji literatur guna membahas solusi yang dapat digunakan untuk membantu permasalahan yang ada di sekolah tersebut berkenaan dengan kegiatan pendampinga olimpiade. Diskusi tersebut berlanjut dengan penentuan penanggung jawab pendamping olimpiade di sekolah dan penyusunan jadwal kegiatan yang akan dilakukan selama pendampingan.

2. Sosialisasi

Kegiatan yang dilakukan setelah merancang semua kegiatan dan terdapat penanggung jawab untuk masing-masing kegaiatan yaitu kegiatan sosialisasi. Kegiatan sosialisasi tersebut dilakukan di UMM dan melibatkan guru dari SMK Muhammadiyah 2 Malang. Sosialisasi ini dilakukan untuk memberikan pengarahan pada guru berkenaan dengan kegiatan pendampingan dan memberikan pelatihan pada guru yang kemudian dilanjutkan dengan kegiatan pelatihan untuk penyusunan Handout. Kegiatan pelatihan ini dilakukan selama 1 kali pertemuan.

3. Pendampingan Pembuatan Handout Sosialisasi yang dilakukan pada kegiatan sebelumnya dilanjutkan dengan kegiatan pendampingan untuk menindak lanjuti kegiatan pendampingan. Kegiatan pendampingan tersebut yaitu membuat handout untuk pembimbingan olimpiade. Pendampingan ini dilakukan di sekolah mitra yang menjadi sasaran pengabdian dan dilakukan selama 3 kali pertemuan. Hasil pendampingan nantinya berupa sebuah handout beserta dengan rencana kegiatan yang akan dilakukan selama kegiatan implementasi.

Pembuatan hand out olimpiade ini digunakan untuk mempermudah siswa dalam belajar soal-soal olimpiade. Pembuatan hand out diarahkan sesuai dengan tahapan polya yang mempunyai 4 tahapan, yaitu : memahami masalah, menyusun rencana, melaksanakan rencana dan melihat kembali.

4. Implementasi kegiatan olimpiade di Sekolah
Setelah kegaiatan pendampingan untuk menyusun Handout untuk selanjutnya dilanjutkan dengan kegiatan implementasi di sekolah. Kegiatan ini dilakukan untuk melihat pelaksanaan dari rencana yang sudah dibuat sebelumnya dan untuk melihat implementasi dari handout yang sudah disusun sebelumnya. Implementasi ini dilakukan kurang lebih selama 5 kali pertemuan. Selain dilakukan secara tatap muka, kegiatan pendampingan juga dilakukan secara online yaitu melalui edmodo, tim tetap melakukan pendampingan dengan memberikan soal pada siswa yang mengikuti olimpiade dengan melalui online yaitu edmodo. Dengan edmodo tim memantau sejauh mana siswa dapat mengerjakan soal olimpiade dan estimasi waktu yang digunakan.

5. Evaluasi dan Refleksi

Kegiatan implementasi selalu diikuti tim pengabdian dengan kegiatan evaluasi guna mengatasi kendala yang terjadi. Selain kegiatan evaluasi, kegiatan selanjutnya yang dilakukan oleh tim pengabdian adalah refleksi untuk keterlaksanaan kegiatan.

Refleksi dilakukan setelah semua kegiatan berjalan, mulai dari perencanaan sampai dengan implementasi. Kegiatan refleksi ini dilakukan oleh tim pengabdian beserta dengan guru pendamping olimpiade dengan jalan tanya jawab dan diskusi. Kegiatan ini dilakukan guna mengetahui apa saja yang terjadi pada saat pelaksanaan berlangsung. Refleksi dilakukan selama 1 pertemuan.

Adapun gambaran pelaksanaan kegiatan yang dilakukan selama pengabdian yaitu :

a. Persiapan yang terdiri dari kegiatan observasi di sekolah dan perencanaan awal

b. Sosialisasi yang di dalamnya terdapat sosialisasi Modul olimpiade dan edmodo

c. Pendampingan

d. Implementasi kegiatan bimbingan

e. Evaluasi dan

f. Refleksi

\section{HASIL DAN PEMBAHASAN}

Kegiatan Pengabdian ini sudah dilaksanakan di SMKM 2 Muhammadiyah Malang, rinciannya ada pada tabel berikut. 
Tabel 2. Kegiatan Pengabdian di SMKM 2 Muhammadiyah Malang

\begin{tabular}{|c|c|c|c|}
\hline $\begin{array}{l}\mathrm{N} \\
\mathrm{O}\end{array}$ & Tanggal & $\begin{array}{l}\text { Uraian } \\
\text { Kegiatan }\end{array}$ & Temuan \\
\hline 1 & $\begin{array}{l}4 \\
\text { Septem } \\
\text { ber } 2018\end{array}$ & $\begin{array}{l}\text { Sosialisasi } \\
\text { ke sekolah } \\
\text { terkait } \\
\text { dengan } \\
\text { rencana } \\
\text { kegiatan } \\
\text { pengabdian. } \\
\text { Kegiatan ini } \\
\text { disambut } \\
\text { dengan baik } \\
\text { oleh ibu } \\
\text { waka } \\
\text { kurikulum. } \\
\text { Beliau } \\
\text { menyampai } \\
\text { kan bahwa } \\
\text { pihak } \\
\text { sekolah } \\
\text { memberi } \\
\text { kesempatan } \\
\text { TIM untuk } \\
\text { berkolabora } \\
\text { si dengan } \\
\text { guru } \\
\text { matematika } \\
\text { dan siswa } \\
\text { untuk } \\
\text { pelaksanaa } \\
\text { n pengabdian }\end{array}$ & $\begin{array}{l}\text { Diterima dan } \\
\text { diberi } \\
\text { kesempatan } \\
\text { untuk } \\
\text { melakukan } \\
\text { pengabdian } \\
\text { di SMKM } 2 \\
\text { Muhammadi } \\
\text { yah Malang }\end{array}$ \\
\hline 2 & $\begin{array}{l}1 \\
\text { Oktober } \\
2018\end{array}$ & $\begin{array}{l}\text { Diskusi } \\
\text { dengan } \\
\text { pihak guru } \\
\text { terkait } \\
\text { dengan } \\
\text { kegiatan } \\
\text { pengabdian. }\end{array}$ & $\begin{array}{l}\text { Dihasilkan } \\
\text { data tentang } \\
\text { kondisi guru } \\
\text { dan siswa di } \\
\text { SMKM } 2 \\
\text { Muhammadi } \\
\text { yah }\end{array}$ \\
\hline 3 & $\begin{array}{l}2 \\
\text { Oktober } \\
2018\end{array}$ & $\begin{array}{l}\text { Penyusuna } \\
\mathrm{n} \quad \text { Modul } \\
\text { olimpiade } \\
\text { yang akan } \\
\text { diberikan } \\
\text { pada saat } \\
\text { workshop } \\
\text { pengabdian. }\end{array}$ & $\begin{array}{l}\text { Modul sudah } \\
\text { siap cetak }\end{array}$ \\
\hline
\end{tabular}

Kegiatan yang belum terlaksana adalah implementasi yang berupa workshop olimpiade, pendampingan dan refleksi kegiatan. Hal ini dikarenakan siswa masih melaksanakan UTS minggu lalu. Pelaksanaan bimbingan olimpiade dilakukan pada hari senin tanggal 15 oktober 2018 di Ruang 306 GKB 1 UMM pukul 11.30 sampai 13.30

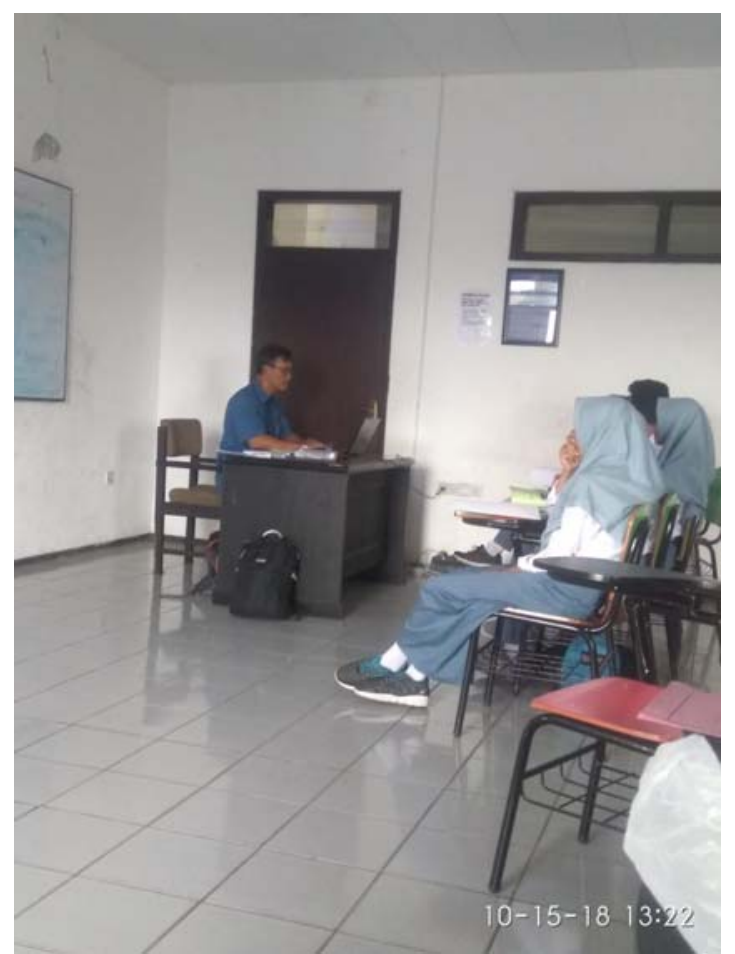

Gambar 1. Kegiatan Pendampingan olimpiade.

\section{SIMPULAN DAN SARAN Simpulan}

Kesimpulan pada kegiatan Pendampingan Dan Pembimbingan Olimpiade Matematika Berbasis Strategi Pemecahan Masalah Polya Pada Siswa SMK Muhammadiyah 2 Malang ini berjalan dengan baik sesuai dengan tujuan yang sudah ditetapkan. Kegiatan ini terdiri dari : 1) Persiapan, 2) Sosialisasi kegiatan, 3) Pendampingan, 4) Pelaksanaan, 5) Evaluasi dan 6) Refleksi. Hasil yang diperoleh dari kegiatan pengabdian ini antara lain yaitu modul pembimbingan olimpiade berdasarkan langkah polya dan hasil catatan kegiatan pendampingan.

\section{Saran}

Saran yang dapat disampaikan dari hasil kegiatan pengabdian ini adalah perlu tindakan yang lebih intensif terkait dengan pendampingan olimpiade. Fokus perhatian yang perlu ditekankan yaitu pelatihan guru pendamping olimpiade agar ke depannya dapat menyampaikan informasi yang diperoleh kepada siswa. 


\section{DAFTAR RUJUKAN}

Bicknell, B. (2008). Gifted Students and the Role of Mathematics Competition. APMC 13, 4(4), 16-20.

IMO. International of Mathematics Olympiad. Diakses pada 17 Oktober 2016 dari www.imo-official.org

Kennedy, L. M., \& Johnson, A. (2007). Guiding Children's Learning of Mathematics.

Prastowo, Andi. 2011. Panduan Kreatif membuat Bahan Ajar Inovatif. Yogyakarta: Diva Press

Sadiman, dkk. 2007. Media Pendidikan. Jakarta: Rajawali

Tim Pengembang Pedoman. 2005. Pedoman Penulisan Buku Pelajaran. Jakarta: Depdiknas 